\title{
MOTIVASI BELAJAR DI SMA NEGERI 2 BURU
}

\author{
Risman Iye and Karim \\ University Iqra Buru \\ INSTITUTE OF ISLAMIC STATE KENDARI \\ rismanive@gmail.com \\ karim@iainkendari.ac.id
}

\begin{abstract}
ABSTRACK
This research is motivated by the phenomenon that all parents want their children's education to be good, so they pay attention and optimize for his child's education. The existence of this need then humans are encouraged to fulfill it. This impulse is called motivation. In this case, of course the role of motivation is very important. How teachers make efforts to be able to grow and give motivation so students do good learning activities. The purpose of this study is (1) To find out whether there is an influence of learning motivation on student achievement in SMA 2 BURU. (2) To find out how much influence the motivation of learning on student achievement in SMA 2 BURU. This research uses a quantitative approach with a descriptive type. The population is at BURU 2 Senior High School, totaling 220 students. using purposive random sampling technique. The sample was 79 students. Research methods using questionnaire and documentation. All instruments have met the requirements as a measurement requirement, because they have tested so that it meets the validity test requirements using product correlation and reliability using Cronbach alpha, and has passed the test precondition. Data analysis using T-test and a large percentage of the influence using the coefficient of determination Adjuster $R$ Square. The results showed that (1) there was a significant effect of Learning Motivation on Learning Achievement evidenced from the value of Tcount> Ttable namely 3.731> 1.9915 and Sig <0.05, namely $0.000<0.05$ (with a level of 5\%). (2) The magnitude of the influence of the Adjusted $R$ square determination coefficient of $35.9 \%$ so that the effect of learning motivation $(X)$, on learning achievement $(Y)$ is weak positive means that if the variable $X$ rises then the variable $Y$ does not rise weakly or together all variables will rise significantly and the remaining $65.1 \%$ is explained by other variables outside the variables used.
\end{abstract}

KEYWORD. Motivation Sma Buru 


\section{INTRUDACTION}

Kata "Motif" diartikan sebagai daya upaya yang mendorong seseorang untuk melakukan sesuatu. Motif dapat dikatakan sebagai daya penggerak dari dalam dan di dalam subjek untuk melakukan aktivitas-aktivitas tertentu demi mencapai tujuan. Bahkan motif dapat diartikan sebagai suatu kondisi intern (kesiapsiagaan). Berawal dari kata "motif" itu, maka motivasi dapat diartikan sebagai daya penggerak yang telah menjadi aktif. Motif menjadi aktif pada saat-saat tertentu, terutama bila kebutuhan untuk mencapai tujuan sangat dirasakan/mendesak. (Sardiman 71-72).

Motivasi adalah dorongan dasar yang menggerakkan seseorang bertingkah laku.

Oleh karena itu, perbuatan seseorang yang didasarkan atas motivasi tertentu dengan motivasi yang disadarinya. motivasi juga dapat dikatakan sebagai perbedaan dapat melaksanakan dan mau melaksanakan. Motivasi adalah kekuatan, baik dari dalam maupun dari luar yang mendorong seseorang untuk mencapai tujuan tertentu yang telah ditetapkan sebelumnya. Motivasi juga dapat diartikan sebagai proses untuk mencoba mempengaruhi orang lain atau orang-orang yang telah dipimpinnya agar melakukan pekerjaan yang diinginkan sesuai dengan tujuan tertentu yang ditetapkan terlebih dahulu (uno, $2008: 1$ ).

Thomson dan Rohani (2004 : 11), menyatakan bahwa motivasi belajar dalam usaha yang disadari oleh pihak guru untuk menimbulkan motif-motif pada diri peserta didik yang menunjang kegiatan kearah tujuan-tujuan belajar. Selain itu menurut menurut Mc.Donald, Motivasi adalah perubahan energi dalam diri seseorang yang ditandai dengan munculnya "feeling" dan didahului dengan tanggapan terhadap adanya tujuan. Dari pengertian yang dikemukakan Mc.Donald ini mengandung tiga elemen penting.

1) Bahwa motivasi itu megawali terjadinya perubahan energi pada diri setiap individu manusia. Perkembangan motivasi akan membawa beberapa perubahan energi di dalam sistem "neurophysiological” yang ada pada organisme manusia.

2) Motivasi ditandai dengan munculnya, rasa/"feeling", afeksi seseorang. Dalam hal ini motivasi relevan dengan persoalan-persoalan kejiwaan, afeksi dan emosi yang dapat menentukan tingkah laku manusia. 
3) Motivasi akan dirangsang karena adanya tujuan. Jadi motivasi dalam hal ini sebenarnya merupakan respon dari suatu aksi, yakni tujuan. Motivasi memang muncul dari dalam diri manusia, tetapi kemunculannya karena terangsang/atau terdorong oleh adanya unsur lain, dalam hal ini adalah tujuan. Tujuan ini akan menyangkut soal kebutuhan.

Dengan ketiga elemen di atas, maka dapat dikatakan bahwa motivasi itu sebagai suatu yang kompleks. Motivasi akan menyebabkan terjadinya suatu perubahan energi yang ada pada diri manusia, sehingga akan bergayut dengan persoalan gejala kejiwaan, perasaan juga emosi, untuk kemudian bertindak atau melakukan sesuatu. Semua ini didorong karena adanya tujuan kebutuhan atau keinginan.

a. Motivasi Instrinsik

Yang dimaksud dengan motivasi instrinsik adalah motif-motif yang menjadi aktif atau berfungsinya tidak perlu dirangsang dari luar, karena dalam diri setiap individu sudah ada dorongan untuk melakukan sesuatu. Sebagai contoh seorang yang senang membaca, tidak usah ada yang menyuruh atau mendorongnya, ia sudah rajin membaca buku-buku untuk dibacanya. Kemudian kalau dilihat dari segi tujuan kegiatan yang dilakukan-nya (misalnya kegiatan belajar), maka yang dimaksud dengan motivasi instrinsik adalah dengan mencapai tujuan yang terkandung di dalam perbuatan belajar itu sendiri. Sebagai contoh konkrit, seorang siswa itu melakukan belajar, karena betul-betul ingin mendapatkan pengetahuan, nilai atau keterampilan agar dapat berubah tingkah lakunya secara konstruktif, tidak karena tujuan yang lain-lain.

Itulah sebabnya motivasi intrinsik dapat juga dikatakan sebagai bentuk motivasi yang didalamnya aktivitas belajar dimulai dan diteruskan berdasarkan suatu dorongan dari dalam diri dan secara mutlak berkait dengan aktivitas belajarnya. Seperti tadi dicontohkan bahwa seseorang belajar, memang benar-benar ingin mengetahui segala sesuatunya, bukan karena ingin pujian atau ganjaran. (Sardiman,2001 : 87-88).

Perlu diketahui bahwa siswa memiliki motivasi intrinsik akan memiliki tujuan menjadi orang yang terdidik, yang berpengetahuan, yang ahli dalam bidang studi tertentu. Satu-satunya jalan untuk menuju ketujuan yang ingin dicapai ialah belajar, tanpa belajar tidak mungkin mendapat pengetahuan, tidak mungkin menjadi ahli. Dorongan yang menggerakkan itu bersumber pada suatu kebutuhan, kebutuhan yang berisikan keharusan 
untuk menjadi orang yang terdidik dan pengetahuan. Jadi memang motivasi itu muncul dari kesadaran diri sendiri dengan tujuan secara esensial, bukan sekedar simbol dan seremonial. (Sardiman,2001 : 87-88).

Terdapat dua jenis motivasi instrinsik, yaitu:

a. Motivasi intrinsik berdasarkan determinasi diri dari dan pilihan personal. Dalam pandangan ini, murid ingin percaya bahwa mereka melakukan sesuatu karena kemauan sendiri, bukan karena kesuksesan atau imbalan eksternal. Minat instrinsik siswa akan eningkat jika mereka mempunyai pilihan dan peluang untuk mengambil tanggug jawab personal atas pembelajaran mereka.

b. Motivasi intrinsik berdasarkan pengalaman optimal. Pengalaman optimal kebanyakan terjadi ketika orang merasa mampu dan dalam tantangan yang bersama anggap tidak terlalu sulit tetapi juga tidak terlalu rendah. (Kompri,2016:232).

b. Motivasi Ekstinsik

Motivasi ekstrinsik adalah motif-motif yang aktif dan berfungsinya karena adanya perangsang d ari luar Sebagai contoh seseorang itu belajar, karena tahu besok paginya akan ada ujian dengan harapan mendapatkan nilai yang baik, sehingga akan dipuji oleh pacarnya, atau temannya. Jadi yang penting bukan karena belajar ingin mengetahui sesuatu, tetapi ingin mendapatkan nilai yang baik, atau agar mendapat hadiah. Jadi kalau dilihat dari segi tujuan kegiatan yang dilakukannya, tidak secara langsung bergayut dengan esensi apa yang dilakukannya itu. Oleh karena itu motivasi ekstinsik dapat juga dikataka sebagai bentuk motivasi yang didalamnya aktivitas belajar dimulai dan diteruskan berdasarkan dorongan dari luar yang tidak secara mutlak berkaitan dengan aktivitas belajar. (Sardiman,2001: 88-89).

Perlu ditegaskan, bukan berarti bahwa motivasi ekstrinsik ini tidak baik dan tidak penting. Dalam kegiatan belajar-mengajar tetap penting. Sebab kemungkinan keadaan siswa itu dinamis, berubah-ubah, dan juga mungkin komponen-komponen lain dalam proses belajar-mengajar ada yang menarik bagi siswa, sehingga diperlukan motivasi intrinsik. (Sardiman,2001: 88-89).

Motivasi ekstrinsik, yaitu melakukan sesuatu unutk mendapatkan sesuatu yang lain (cara unutk mencapai tujuan). Motivasi ekstrinsik sering dipengaruhi oleh intensif 
eksternal seperti imbalan dan hukuman. Misalnya, murid belajar keras dalam menghadapi ujian untuk

\section{Daftar Pustaka}

Sam, B., Iye, R., Ohoibor, M., Umanailo, M. C. B., Rusdi, M., Rahman, A. B. D., \& Hajar, I. (2019). Female Feminism in the Customary Island of Buru. Int. J. Sci. Technol. Res, 8(8), 1877-1880.

Susiati, S., Iye, R., \& Suherman, L. O. A. (2019). Hot Potatoes Multimedia Applications in Evaluation of Indonesian Learning In SMP Students in Buru District. ELS Journal on Interdisciplinary Studies in Humanities, 2(4), 556-570.

Susiati, S., Iye, R., \& Suherman, L. O. A. (2019). Hot Potatoes Multimedia Applications in Evaluation of Indonesian Learning In SMP Students in Buru District. ELS Journal on Interdisciplinary Studies in Humanities, 2(4), 556-570.

Iye, R., \& Susiati, S. (2018). NILAI EDUKATIF DALAM NOVEL SEBAIT CINTA DI BAWAH LANGIT KAIRO KARYA MAHMUD JAUHARI ALI (Educative Values in Sebait Cinta di Bawah Langit Kairo by Mahmud Jauhari Ali). Sirok Bastra, 6(2), 185-191.

Susiati, S. (2018). Homonim bahasa kepulauan tukang besi dialek kaledupa di kabupaten wakatobi [the homonymon of tukang besi island languange in kaledupa dialect at wakatobi regency]. Totobuang, 6(1), 109.

Susiati, S. (2020). The Concept Of Togetherness In The Films" Aisyah Biarkan Kami Bersaudara" By Herwin Novianto.

Nurhayati, N., \& Said, I. (2019). Emosi Verbal Suku Bajo Sampela. Sosial Budaya, 16(2), 114126.

Susiati, S., \& Iye, R. (2018). Kajian Geografi Bahasa dan Dialek di Sulawesi Tenggara: Analisis Dialektometri. Gramatika: Jurnal Ilmiah Kebahasaan dan Kesastraan, 6(2), 137-151.

Susiati, S. The Concept Of Togetherness In The Films" Aisyah Biarkan Kami Bersaudara" By Herwin Novianto.

Iye, R., Susiati, S., \& Karim, K. (2020). Citra Perempuan dalam Iklan Sabun Shinzui. Sang Pencerah: Jurnal Ilmiah Universitas Muhammadiyah Buton, 6(1), 1-7.

Susiati, S. (2020). The Concept Of Togetherness In The Films" Aisyah Biarkan Kami Bersaudara" By Herwin Novianto.

Susiati, S. (2020). Eksistensi Manusia Dalam Film" Aisyah Biarkan Kami Bersaudara" Karya Herwin Novianto.

Iye, R. (2018). Tuturan dalam Prosesi Lamaran Pernikahan di Tomia Kabupaten Wakatobi. Jurnal Totobuang, 6(2).

Susiati, S. Konsep Pertentangan Dalam Film" Aisyah Biarkan Kami Bersaudara" Karya Herwin Novianto.

Wael, A., Setiaji, A. B., Pannyiwi, R., Lapandewa, L., Asshagab, S. M. N., Jouhari, B., ... \&

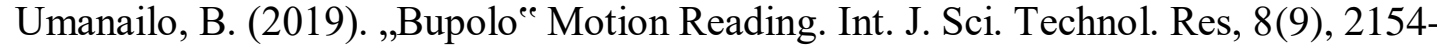
2158.

Susiati, S. (2020). Konsep Kebersamaan Dalam Film" Aisyah Biarkan Kami Bersaudara" Karya Herwin Novianto.

Wael, A., Setiaji, A. B., Pannyiwi, R., Lapandewa, L., Asshagab, S. M. N., Jouhari, B., ... \& Umanailo, B. "Bupolo" Motion Reading.

Iye, R. H. (2019). NILAI-NILAI MORAL DALAM TOKOH UTAMA PADA NOVEL SATIN MERAH KARYA BRAHMANTO ANINDITO DAN RIE YANTI. TELAGA BAHASA,(7), 2, 195-206. 
Iye, R. J1 Prof Dr HAR Basalamah No, and Namlea-Kab Buru.". TUTURAN DALAM PROSESI LAMARAN PERNIKAHAN DI TOMIA KABUPATEN WAKATOBI." Kontemporer. Bandung: PT Remaja.

Iye, R., Tenriawali, A. Y., Susiati, A., \& Buton, D. (2020). Makna dan Fungsi Emosi Mahasiswa Kota Baubau dalam Ranah Demonstrasi: The Meaning And Emotional Function Of Students Of Baubau City In The Demonstration Plan. Uniqbu Journal of Social Sciences, 1(1), 25-37.

Referen, B. Konsep teori de Saussure ini dikembangkan lagi oleh Richard dan Ogdent (dalam Chaer, 1994: 287) Dalam sebuah bagan makna berupa segi tiga yang menghubungkan tiga komponen makna, yaitu bentuk, konsep, dan referen. Bagannya adalah sebagai berikut.

Masiri, R., Iye, R., Harziko, H., Malik, S., \& Karim, K. (2020). ERROR ANALYSIS IN STUDENTS'CLASSROOM DISCUSSION AT MTS LKMD WAEMOLI:(Analisis Kesalahan Berbahasa Dalam Diskusi Siswa Kelas VIII MTS LKMD Waemoli). Uniqbu Journal of Social Sciences, 1(2), 56-62.

Susiati, S. (2020). Semantik: Teori Semantik, Relasi Makna, Marked, Dan Unmarked.

Iye, R., Tenriawali, A. Y., Susiati, A., \& Buton, D. (2020). Makna dan Fungsi Emosi Mahasiswa Kota Baubau dalam Ranah Demonstrasi: The Meaning And Emotional Function Of Students Of Baubau City In The Demonstration Plan. Uniqbu Journal of Social Sciences, 1(1), 25-37.

Susiati, S., Masniati, A., \& Iye, R. (2021). Kearifan Lokal Dalam Perilaku Sosial Remaja Di

Desa Waimiting Kabupaten Buru. Sang Pencerah: Jurnal Ilmiah Universitas Muhammadiyah Buton, 7(1), 8-23.

Iye, R., Tenriawali, A. Y., Susiati, A., \& Buton, D. (2020). Makna dan Fungsi Emosi Mahasiswa Kota Baubau dalam Ranah Demonstrasi: The Meaning And Emotional Function Of Students Of Baubau City In The Demonstration Plan. Uniqbu Journal of Social Sciences, 1(1), 25-37.

BAUBAU, T. O. FOLLOW THE EVENTS IN THE INDONESIAN LANGUAGE EXPRESSIVE SAID TRANSACTION IN THE TRADITIONAL MARKET.

Iye, R. (2018). Tuturan emosi mahasiswa kota baubau dalam ranah demonstrasi.

Susiati, S., Masniati, A., \& Iye, R. (2021). Kearifan Lokal Dalam Perilaku Sosial Remaja Di

Desa Waimiting Kabupaten Buru. Sang Pencerah: Jurnal Ilmiah Universitas Muhammadiyah Buton, 7(1), 8-23.

Susiati, S. Fenomena Tuturan Emosi Verbal Bahasa Indonesia Suku Bajo Sampela.

Iye, Risman, A. Yusdianti Tenriawali, Azwan Susiati, and Darwis Buton. "MAKNA DAN FUNGSI EMOSI MAHASISWA KOTA BAUBAU DALAM RANAH DEMONSTRASI: THE MEANING AND EMOTIONAL FUNCTION OF STUDENTS OF BAUBAU CITY IN THE DEMONSTRATION PLAN." Uniqbu Journal of Social Sciences 1, no. 1 (2020): 25-37.

Harziko, H., Said, I. M., \& Darwis, K. (2018). FOLLOW THE EVENTS IN THE INDONESIAN LANGUAGE EXPRESSIVE SAID TRANSACTION IN THE TRADITIONAL MARKET TOWN OF BAUBAU. JURNAL ILMU BUDAYA, 6(1).

Susiati, S., Tenriawali, A. Y., Nursin, N., Nacikit, J., \& Mukadar, S. (2020). NILAI EDUKASI DALAM NOVEL PARTIKEL KARYA DEWI LESTARI:(The Value of Education in Particle Novels by Dewi Lestari). Uniqbu Journal of Social Sciences, 1(3), 176-183.

Yusnan, M., Kamasiah, R. I., Karim, H., \& Bugis, R. (2020). Alih Kode dan Campur Kode pada Novel Badai Matahari Andalusia Karya Hary El-parsia: Transfer Code And Mix Code In Novels Badai Matahari Andalusia Karya Hary El-parsia. Uniqbu Journal of Social Sciences, 1(1), 1-12.

Yusnan, M., Kamasiah, R. I., Karim, H., \& Bugis, R. (2020). ALIH KODE DAN CAMPUR KODE PADA NOVEL BADAI MATAHARI ANDALUSIA KARYA HARY EL- 
PARSIA: Transfer code and mix code in Novels Badai Matahari Andalusia Karya Hary El-Parsia. Uniqbu Journal of Social Sciences, 1(1), 1-12.

Iye, R. WRITING SKILLS IN SMP USWATUN HASANAH. BURU DISTRICT.

Karim, A. B., \& Yusnan, M. Aspek Spiritual Dalam Novel Tuhan Izinkan Aku Menjadi Pelacur Karya Muhidin M Dahlan: Spiritual Aspects in the Lovely of God Let Me Become a Property of Muhidin M Dahlan. Uniqbu Journal of Social Sciences, 1(1), 61-71.

Bin-Tahir, S. Z., Suriaman, A., Hanapi, H., Iye, R., \& Umanailo, M. C. B. (2020). Development of Buru Local Language Conversation Material Based on the CommunicativeInteractive Approach for Elementary School Students. Solid State Technology, 63(2s).

Iye, R. WRITING SKILLS IN SMP USWATUN HASANAH. BURU DISTRICT.

Susiati, S., Tenriawali, A. Y., Nursin, N., Nacikit, J., \& Mukadar, S. (2020). NILAI EDUKASI DALAM NOVEL PARTIKEL KARYA DEWI LESTARI:(The Value of Education in Particle Novels by Dewi Lestari). Uniqbu Journal of Social Sciences, 1(3), 176-183.

Karim, A. B., \& Yusnan, M. (2020). Aspek Spiritual Dalam Novel Tuhan Izinkan Aku Menjadi Pelacur Karya Muhidin M Dahlan: Spiritual Aspects in the Lovely of God Let Me Become a Property of Muhidin M Dahlan. Uniqbu Journal of Social Sciences, 1(1), 61-71.

Andini, K. NILAI BUDAYA SUKU BAJO SAMPELA DALAM FILM THE MIRROR NEVER LIES KARYA KAMILA ANDINI.

Umanailo, M. C. B., Hentihu, I., Umanailo, R., Nawawi, M., Pulhehe, S., Ohoibor, M., ... \& MANGESA, R. (2018). Comprehension To Village.

Andini, K. NILAI BUDAYA SUKU BAJO SAMPELA DALAM FILM THE MIRROR NEVER LIES KARYA KAMILA ANDINI.

Umanailo, M., Hentihu, I., Umanailo, R., Nawawi, M., Pulhehe, S., Ohoibor, M., .. \& Musa, M. N. D. (2017). Comprehension To Village (No. yuavq). Center for Open Science.

Susiati, S. (2020). Nilai Budaya Suku Bajo Sampela Dalam Film The Mirror Never Lies Karya Kamila Andini.

Susiati, S., \& Iye, R. (2018). Kajian Geografi Bahasa dan Dialek di Sulawesi Tenggara: Analisis Dialektometri. Gramatika: Jurnal Ilmiah Kebahasaan dan Kesastraan. 6 (2), 137-151.

Rabadia, E. S. O., \& Hanapi, H. STUDENTS'WRITING SKILL THROUGH CLUSTERING TECHNIQUE.

Sam, B., Iye, R., Ohoibor, M., \& Umanailo, M. CB, Rusdi, M., Rahman, ABD, \& Hajar, I.(2019). Female Feminism in the Customary island of Buru, 1877-1880.

Lafamane, F. (2020). Perkembangan Teori Sastra (suatu Pengantar).

Bin Tahir, S. Z., Iye, R., Tenriawali, A. Y., Karim, Z. Z. Z., \& Umanailo, M. C. B. (2020, March). Cia-cia vocational inventoryization in Buru district. In Proceedings of the International Conference on Industrial Engineering and Operations Management (No. 0, pp. 25092518).

Nurlatu, J., Bugis, R. K., Karim, K., Azwan, A., \& Iye, R. (2020). Penggunaan Dieksis Sopan Santun Mahasiswa Universitas Iqra Buru. Jurnal Ilmiah FONEMA: Jurnal Edukasi Bahasa dan Sastra Indonesia, 3(2), 154-164.

Susiati, S. PERWUJUDAN SIMILE OLEH MERARI SIREGAR DALAM NOVEL AZAB DAN SENGSARA.

Susiati, S. Dialektometri Segitiga: Hubungan Kekerabatan Bahasa Di Sulawesi Tenggara (Bahasa Wakatobi, Bahasa Cia-Cia, Bahasa Pancana, Bahasa Kioko, Bahasa Tolaki).

Lafamane, F. (2020). Perkembangan Teori Sastra (suatu Pengantar).

Susiati, S., \& Mufidati, E. (2020). An Indonesian National English Textbook for Secondary Level: Is It Qualified Enough?. Jurnal VARIDIKA, 32(1), 118-124.

Yulismayanti, H., Iye, R., \& Susiati, S. Z. B. T. (2020). VARIATIVE METHOD IN IMPROVING STUDENT LEARNING MOTIVATION IN PANDEMIC COVID-19 SITUATIONS. Journal of Critical Reviews, 7(5), 1584-1595. 
Susiati, S. Dialektometri Segitiga: Hubungan Kekerabatan Bahasa Di Sulawesi Tenggara (Bahasa Wakatobi, Bahasa Cia-Cia, Bahasa Pancana, Bahasa Kioko, Bahasa Tolaki).

Yulismayanti, H., Iye, R., \& Susiati, S. Z. B. T. (2020). VARIATIVE METHOD IN IMPROVING STUDENT LEARNING MOTIVATION IN PANDEMIC COVID-19 SITUATIONS. Journal of Critical Reviews, 7(5), 1584-1595.

Lafamane, Felta. "KAJIAN STILISTIKA (Komponen Kajian Stilistika)." (2020).

Susiati, Susiati. "Makian Bahasa Wakatobi Dialek Kaledupa." (2020).

Bassalamah, J. P. D. H. (2020). MAKIAN BAHASA WAKATOBI DIALEK KALEDUPA.

Susiati, S. risman iye. 2020.“. Dialektometri Segitiga: Hubungan Kekerabatan Bahasa Di Sulawesi Tenggara (bahasa Wakatobi, Bahasa Cia-cia, Bahasa Pancana, Bahasa Kioko, Bahasa Tolaki).” OSF Preprints. July, 21.

Yulismayanti, Y., Harziko, H., \& Irmawati, A. Kemampuan Menemukan Nilai Edukatif Dalam Cerpen Juru Masak Karya Damhuri Muhammad Siswa Kelas X SMA Negeri 12 Buru:(the Avility to Find Educative Values in Story of Master Teacher Work of Damhuri Muhammad at SMP 12 Buru). Uniqbu Journal of Social Sciences, 1(2), 3548.

Yulismayanti, Y., Harziko, H., \& Irmawati, A. (2020). Kemampuan Menemukan Nilai Edukatif Dalam Cerpen Juru Masak Karya Damhuri Muhammad Siswa Kelas X SMA Negeri

12 Buru:(the Avility to Find Educative Values in Story of Master Teacher Work of Damhuri Muhammad at SMP 12 Buru). Uniqbu Journal of Social Sciences, 1(2), 3548.

Susiati, S. (2020). Pentingnya Melestarikan Bahasa Daerah.

UNIQBU, P. (2019). TUTURAN EMOSI MAHASISWA KOTA BAU BAU.

Susiati, Y. T. Risman Iye. A. Kesantunan Imperatif Bahasa Indonesia Suku Bajo Sampela: Balai Pembinaan dan Pengembangan Bahasa. 2018. Kongres Bahasa Indonesia (No. 12, pp. 1-6). Report.I

Tenriawali, A. Y., Azwan, R. B., Taufik, M., Harziko, R. I., \& Bin-Tahir, S. Z. Politeness of Language Use amongst Millennial Generation in Namlea City.

Umanailo, M. C. B. (2021). Politeness of Language Use amongst Millennial Generation in Namlea City.

Nurlatu, J., Bugis, R. K., \& Iye, R. Penggunaan Dieksis Sopan Santun Mahasiswa Universitas Iqra Buru.

Hanapi, H. Gaya Bahasa pada Novel Piano dalam Kotak Kaca Karya Agnes Jessica. Uniqbu Journal of Social Sciences, 1(1), 344007.

Sam, B., Iye, R., Ohoibor, M., Umanailo, M. C. B., Rusdi, M., Rahman, A. B. D., \& Hajar, I. (2019). Female Feminism in the Customary Island of Buru. Int. J. Sci. Technol. Res, 8(8), 1877-1880.

Iye, R. (2018). Tuturan emosi mahasiswa kota baubau dalam ranah demonstrasi [emotional speech of the students in baubau city in the demonstration]. TOTOBUANG, 6 (1), $125,138$.

Iye, R., \& Susiati, S. (2018). NILAI EDUKATIF DALAM NOVEL SEBAIT CINTA DI BAWAH LANGIT KAIRO KARYA MAHMUD JAUHARI ALI (Educative Values in Sebait Cinta di Bawah Langit Kairo by Mahmud Jauhari Ali). Sirok Bastra, 6 (2), 185-191.

Susiati, S., \& Iye, R. (2018). Kajian Geografi Bahasa dan Dialek di Sulawesi Tenggara: Analisis Dialektometri. Gramatika: Jurnal Ilmiah Kebahasaan dan Kesastraan. 6 (2), 137-151.

Susiati, S., Iye, R., \& Suherman, L. O. A. (2019). Hot Potatoes Multimedia Applications in Evaluation of Indonesian Learning In SMP Students in Buru District. ELS Journal on Interdisciplinary Studies in Humanities, 2(4), 556-570.

Umanailo, M. C. B., Hentihu, I., Umanailo, R., Nawawi, M., Pulhehe, S., Ohoibor, M., ... \& Bugis, R. I. K. I. (2018). Pemahaman Untuk Desa. 
Iye, R. J1 Prof Dr HAR Basalamah No, and Namlea-Kab Buru.". TUTURAN DALAM PROSESI LAMARAN PERNIKAHAN DI TOMIA KABUPATEN WAKATOBI." Kontemporer. Bandung: PT Remaja.

Susiati, S., \& Iye, R. (2018). Kajian Geografi Bahasa dan Dialek di Sulawesi Tenggara: Analisis Dialektometri. Gramatika: Jurnal Ilmiah Kebahasaan dan Kesastraan, 6(2), 137-151 
Iye, R., Susiati, S., \& Karim, K. (2020). Citra Perempuan dalam Iklan Sabun Shinzui. Sang Pencerah: Jurnal Ilmiah Universitas Muhammadiyah Buton, 6(1), 1-7.

UNIQBU, P. (2019). TUTURAN EMOSI MAHASISWA KOTA BAU BAU.

Risman iye. Arlinda. 2017. Nilai Moral pada Novel Tuhan Izinkan aku menjadi pelacur karya M. Dahlan. Univeristas Iqra Buru. (7). 2.

YANTI, K. NILAI-NILAI MORAL DALAM TOKOH UTAMA PADA NOVEL SATIN MERAH.

Yusdianti Tenriawali Susiati. Risman Iye. A. Kesantunan Imperatif Bahasa Indonesia Suku Bajo Sampela: Balai Pembinaan dan Pengembangan Bahasa.2018. Kongres Bahasa Indonesia. Volume 12. Report number 12. Pages 1-6 Publisher. Balai Pembinaan dan Pengembangan Bahasa.

Risman Iye.2018. TUTURAN DALAM PROSESI LAMARAN PERNIKAHAN DI TOMIA KABUPATEN WAKATOBI. TOTOBUANG, 6 (2), 183, 199.

Risman Iye dan Harziko. NILAI-NILAI MORAL DALAM TOKOH UTAMA PADA NOVEL SATIN MERAH KARYA BRAHMANTO ANINDITO DAN RIE YANTI. TELAGA BAHASA, (7) 2, 195-206.

Karim dan Risman Iye. 2019. PRAANGGAPAN PAMFLET SOSIALISASI PELESTARIAN LINGKUNGAN DI KABUPATEN WAKATOBI.TOTOBUANG, 7 (2), 213-224.

Risman iye dan Azwan. 2019. PERWUJUDAN ADJEKTIVA BAHASA SULA DIALEK FALAHU DI DESA SAWAH KECAMATAN NAMLEA. Mlangun Jurnal Ilmiah Kebahasaan \& Kesastraan, (16) 2. 121-131. UNIQBU, P. (2019). TUTURAN EMOSI MAHASISWA KOTA BAU BAU. 